\title{
CHEMICAL PRETREATMENT OF SAVANNAH RIVER SITE NUCLEAR WASTE FOR DISPOSAL
}

\author{
by \\ D. T. Hobbs \\ Westinghouse Savannah River Company \\ Savannah River Site \\ Aiken, South Carolina 29808 \\ D. D. Walker
}

A document prepared for:

Chemical Pretreatment of Nuclear Waste for Disposal

at Washington, DC

from $8 / 23 / 92$ thru $8 / 28 / 92$

DOE Contract No. DE-AC09-89SR18035

This paper was prepared in connection with work done under the above contract number with the U.S.

Department of Energy. By acceptance of this paper, the publisher and/or recipient acknowledges the U. S. Government's right to retain a nonexclusive, royalty-free license in and to any copyright covering this paper, along with the right to reproduce and to authorize others to reproduce all or part of the copyrighted paper. 


\section{DISCLAIMER}

This report was prepared as an account of work sponsored by an agency of the United States Government. Neither the United States Government nor any agency thereof, nor any of their employees, makes any warranty, express or implied, or assumes any legal liability or responsibility for the accuracy, completeness, or usefulness $c$ any information, apparatus, product, or process disclosed, or represents that its use would not infringe privately owned rights. Reference herein to any specific commercial product, process, or service by trade name, trademark, manufacturer, or otherwise does not necessarily constitute or imply its endorsement, recommendation, or favoring by the United States Government or any agency thereof. The views and opinions of authors expressed herein do not necessarily state or reflect those of the United States Government or any agency thereof.

This report has been reproduced directly from the best available copy.

Available to DOE and DOE contractors from the Office of Scientific and Technical Information, P. O. Box 62, Oak Ridge, TN 37831; prices available from (615) $576-8401$.

Available to the public from the National Technical Information Service, $U$. $S$. Department of Commerce, 5285 Port Royal Rd., Springfield, VA 22161 
WSRC-MS-92-144

\title{
CHEMICAL PRETREATMENT OF SAVANNAH RIVER SITE NUCLEAR WASTE FOR DISPOSAL
}

\author{
DTH Row
}

D.T. Hobbs and D.D. Walker

\author{
Westinghouse Savannah River Company \\ Savannah River Technology Center \\ Aiken, South Carolina 29808
}

\section{INTRODUCTION}

The Savannah River Site (SRS), located near Aiken, SC, is presently the nation's primary source of nuclear materials for defense, space, medical, and energy applications. The site, which was built in the early 1950's, comprises over 750 square kilometers of land with extensive support facilities. Nuclear materials produced at SRS are generated in heavy-water reactors by irradiating appropriate target materials with neutrons from urarium fuels and then chemically separating the products in two on-site processing plants.

Since start-up over 400 million liters of high level waste have been generated. This waste has been evaporated to about 130 million liters, which is now stored in large underground tanks. The principal radionuclides in the waste are ${ }^{90} \mathrm{Sr}$ and ${ }^{137} \mathrm{Cs}$. Approximately $10 \%$ of the waste consists of iron, manganese, uranium, and aluminum oxides and hydroxides, which are precipitated upon neutralization of the acidic nilric acid wastes produced in the chemical separation operations. These solids are referred to as sludge. The sludge contains most of the strontium and small amounts oi actinides not recovered in the reprocessing plants. The remainder of the waste is liquid and salt cake, which consists primarily of sodium nitrate, sodium nitrite, sodium alıminate, and sowum hydroxide. This waste contains ${ }^{137} \mathrm{Cs}$ and traces of other soluble radionur 'ijdes.

The HLW will be pretreated to reduce the amount of waste ivhir 1 ise.sec of in the

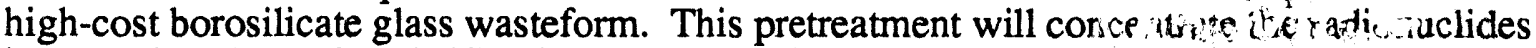
in a small volume for vitrification. The rema ling high-volume wevell waste will be disposed of in a cement wasteform referred to as Saltstone. A scternat: d aglam of the pretreatment and final disposal of HLW at the SRS is provided in Figure $t$.

HLW pretreatment operations, referred to as In-Tank Procening will be curred out in waste tanks which have been modified for chemical processing. T. Thl Processing consists of two separate processes, Extended Sludge Processing a a Tre recinitation. A schematic diagram of the Extended Sludge Piocessing operation $, \ldots, c, d$ in Figure 2. The Extended Sludge Processing operation will prepare the sludge fractivi of $\mathrm{HLW}$ for feed to the Defense Waste Processing Facility (DWPF) for vitrification. A sch rmatic diagram of the In-Tank Precipitation process is provided in Figure 3. The In-Tank Precipitation Process will remove greater than $99.9 \%$ of radioactivity in the salt fraction of HLW into a solid phase which will be combined with sludge and vitrified. The decontaminated salt solution will be disposed of in a cement wasteform, Saltstone. 


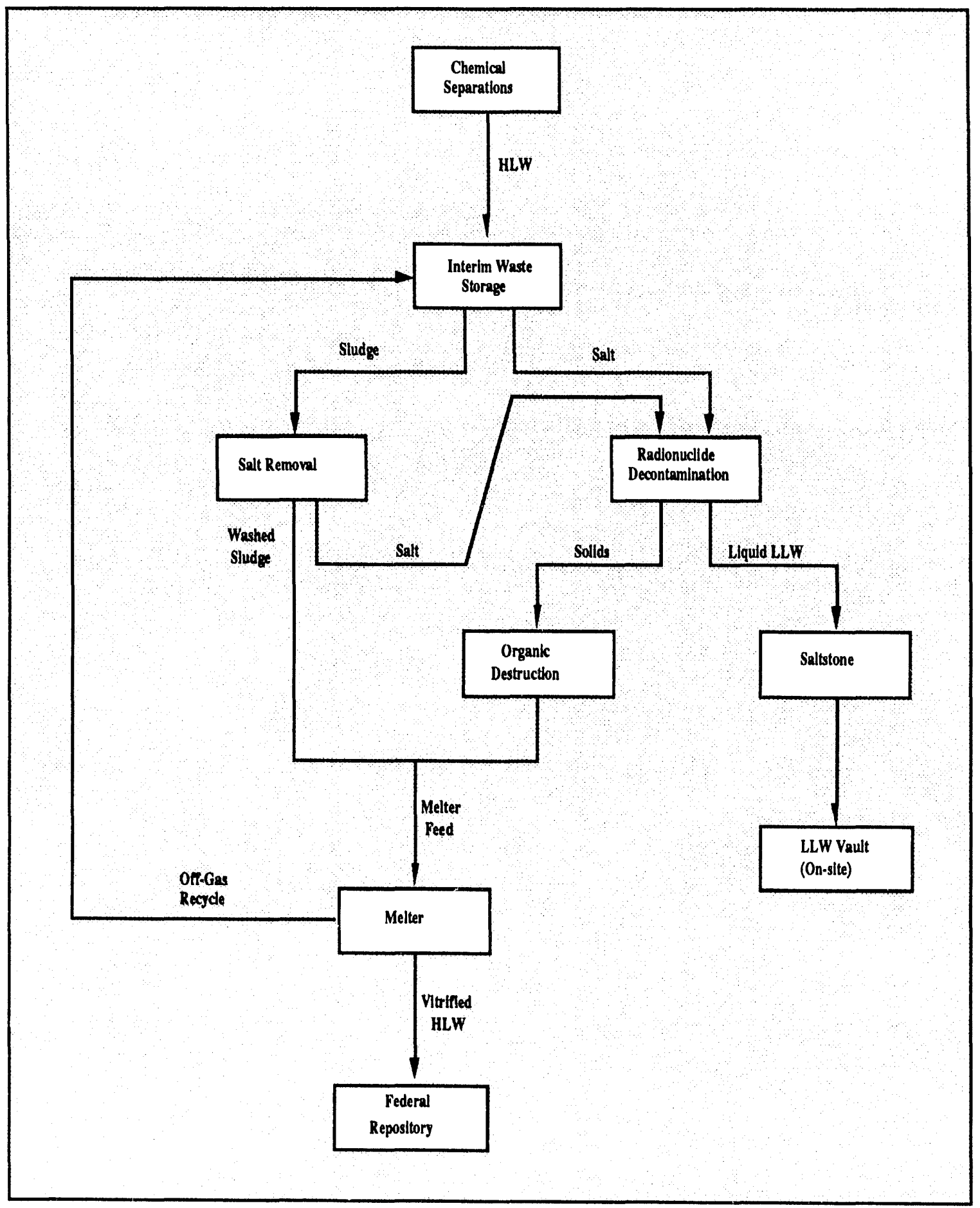

Figure 1. Schematic Diagram for Pretreatment and Disposal of High-Level Waste at the Savannah River Site.

\section{EXTENDED SLUDGE PROCESSING}

The purpose of the Extended Sludge Processing (ESP) operation is to reduce the solids content of the sludge and ensure its compatibility with the borosilicate glass wasteform. Reducing the soluble salts content results in significant cost savings by reducing the total amount of glass produced in the DWPF. The soluble salts will be reduced by a seric' of batch washings. A scnematic flow diagram of the ESP operation is presented in Figure 2. 


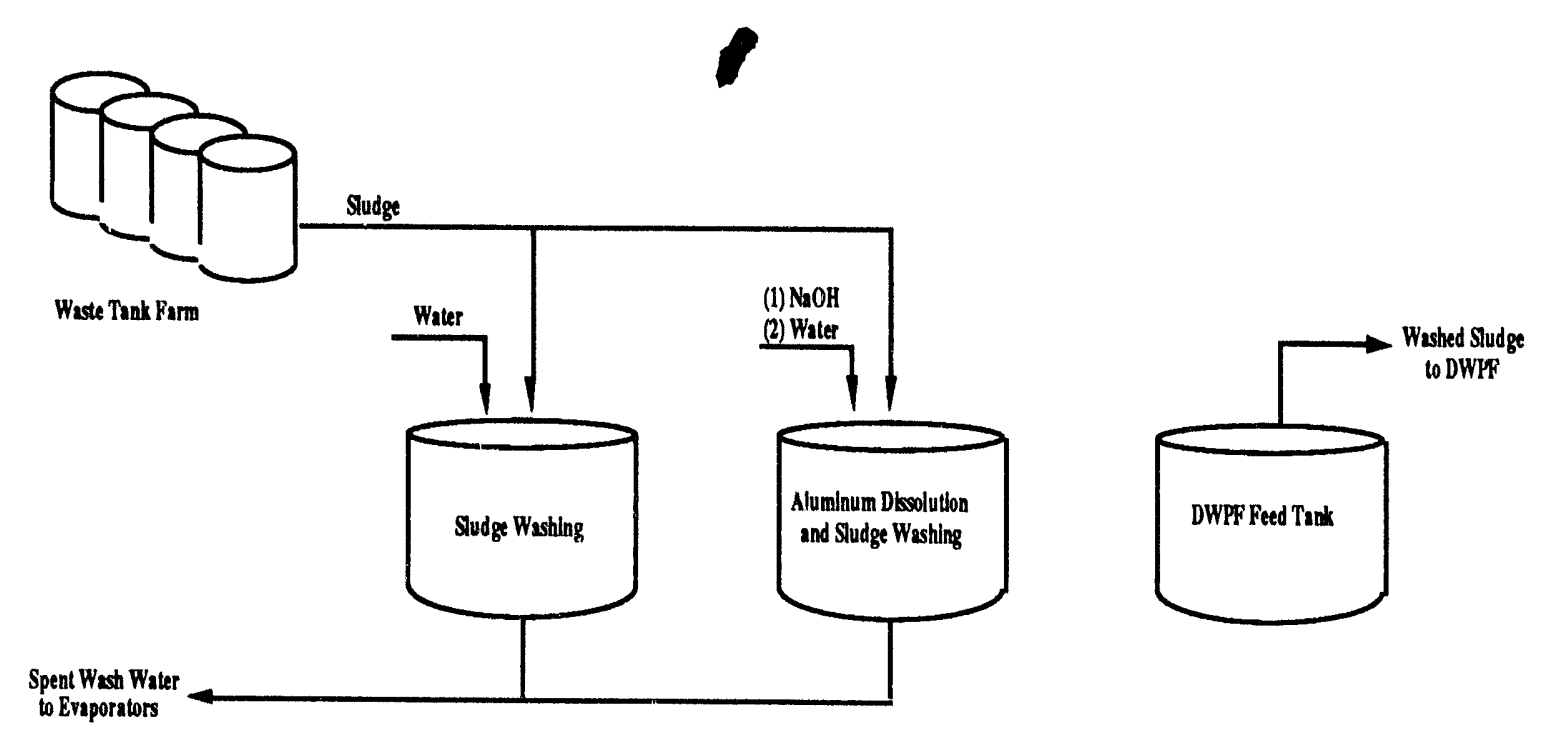

Figure 2. Schematic Diagram of the ESP Operation.

Sludge processing will occur in three 4.9 million-liter, HLW storage tanks which have been modified for processing. Sludge wastes will be removed from storage tanks and transferred into one of two tanks in which the sludge is washed concurrently. The sludge is contacted with wash water for a period of time to ensure a homogeneous mixture, the agitation is then stopped, and the solids allowed to gravity settle. The liquid is then decanted from the settled solids. This series of steps is repeated until the soluble salt content in the liquid phase is reduced to $\leq 2.5$ weight percent of the total solids content. Wash solutions produced in ESP will be transferred to an evaporator system or reused in dissolving saltcake, depending on the salt concentration. The wash water from the first tank will be reused to wash sludge in the second tank.

For sludge wastes which have a high aluminum content, an additional step is added to dissolve the aluminum prior to water washing. The sludge is heated with sodium hydroxide to dissolve approximately $75 \%$ of the aluminum. After dissolution, the tank agitation is stopped, the undissolved sludge solids are allowed to gravity settle, and the supernatant liquid is decanted. The remaining sludge will then be washed as described above. Aluminum dissolution will be carried out only in one of the three processing tanks.

After washing has been completed, both batches of sludge will be combined into one tank for storage. From this tank, washed sludge will be transferred to the DWPF through underground transfer lines. The next batch of sludge for the DWPF will then be produced using the two empty tanks.

\section{ALUMINUM DISSOLUTION CHEMISTRY}

One of the major constituents of SRS HLW is aluminum. Aluminum is used for cladding and alloying materials in fuel and target assemblies. If left in the sludge, aluminum adversely affects glass viscosity and adds to the volume of waste processed in the DWPF. Aluminum is present in both the supernatant liquid and in the sludge wastes. In the supernatant liquid, aluminum is present as the aluminate ion, $\mathrm{Al}(\mathrm{OH})_{4}{ }^{-}$. In sludge, aluminum is present in three forms, alumina trihydrate or gibbsite, alumina monohydrate or boehmite, and sodium aluminosilicate. Only the gibbsite is readily soluble at the conditions which will be used in the ESP operation. The chemical reaction for the dissolution of gibbsite is given below:

$$
\mathrm{Al}_{2} \mathrm{O}_{3} \cdot 3 \mathrm{H}_{2} \mathrm{O}(\mathrm{s})+2 \mathrm{NaOH}(\mathrm{aq}) \quad \cdots \quad 2 \mathrm{NaAl}(\mathrm{OH})_{4}(\mathrm{aq})
$$


To dissolve the gibbsite, $50 \mathrm{wt} . \%$ sodium hydroxide solutions will be added to the sludge slurry in the processing tank to provide a minimum initial ratio of three moles of free hydroxide per mole of acid-soluble gibbsite, and a final liquid phase free hydroxide concentration of 3 molar. The sludge slurry will be steam heated to between 80 and $90^{\circ} \mathrm{C}$ and agitated until all of the gibbsite dissolves. It is estimated that it take approximately three days for the gibbsite to dissolve.

\section{FULL-SCALE ESP DEMONSTRATION}

A full-scale demonstration of ESP was carried out in 1982-1983. Approximately 473,000 liters of sludge were successfully transferred a distance of about 3.2 kilometers from the storage tank in F-Area to the processing tank in H-Area via the inter-area transfer line. The sludge was slurried in the processing tanks using three slurry pumps. This sludge had a high aluminum content, and therefore, was treated with sodium hydroxide to dissolve the gibbsite. Seventy-nine percent of the total aluminum was removed by aluminum dissolution. After aluminum dissolution, the sludge was washed with three consecutive batches of wash water which reduced the soluble salt content to the DWPF feed requirement of $\leq 2.5 \mathrm{wt} . \%$. The final solids content of the settled sludge was $14 \mathrm{wt} . \%$.

The slurry pumps used in the demonstration are variable-speed centrifugal pumps with a flow capacity of 250 liters $/ \mathrm{sec}$ and a nominal mixing radius of $12 \mathrm{f}$ meters powered by a 224 $\mathrm{kJ} / \mathrm{sec}$ motor. The pump is constructed of type 304L stainless steel with graphite sleeve bushings for the bottom seal. Since the demonstration, the design of the mechanical seals has been changed to decrease the bearing water leak rate.

\section{IN-TANK PRECIPITATION PROCESS}

The purpose of the In-Tank Precipitation (ITP) process is to concentrate the radio-cesium and radio-strontium into a small-volume solid phase which can be separated from the liquid phase and vitrified with the washed sludge in the DWPF. In this process (see Figure 3), sodium tetraphenylborate and monosodium titanate are added to a waste tank containing redissolved salt and supernatant liquid. The cesium and potassium precipitates as cesium tetraphenylborate and potassium tetraphenylborate. The strontium is adsorbed by the monosodium titanate, which remiains a solid throughout the process. The supernate, with most of its radioactive constituents now in solid form, is then filtered through sintered stainless steel filters with a $0.5 \mu \mathrm{m}$ pore size. 


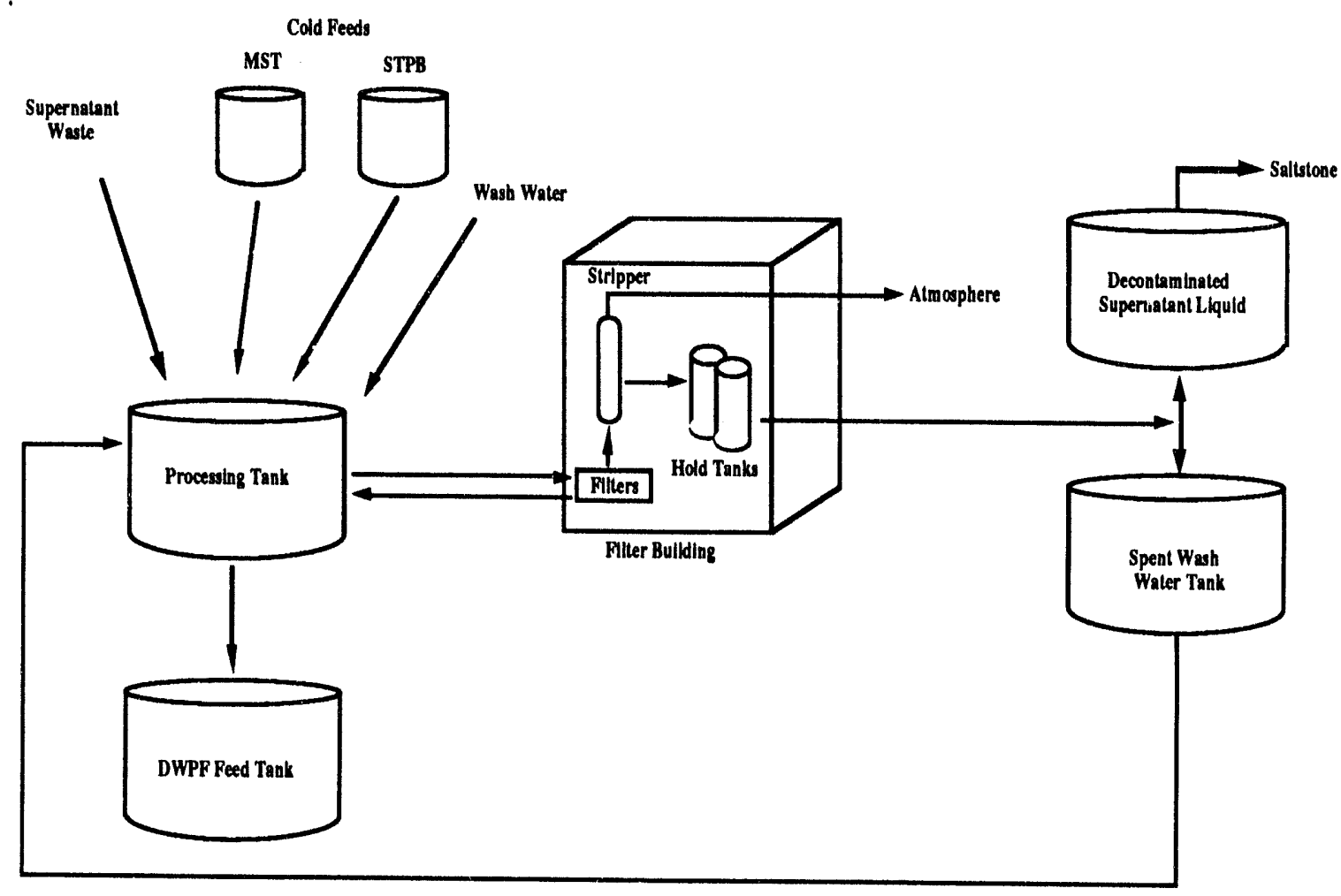

Figure 3. Schematic Diagram of the In-Tank Precipitation Process

The decontaminated supernate filtrate will be disposed of as a low-level radioactive waste in a cement wasteform, Saltstone. The cement wasteform will be placed in an engineered vault onsite. The precipitate, which is unable to pass through the filters, is recycled back to the waste tank. This material is then concentrated and washed to remove residual salts. The washed precipitate, containing virtually all the radioactivity of the original supernate, will be incorporated into borosilicate glass in the DWPF.

\section{ITP PROCESS CHEMISTRY}

In the precipitation process, tetraphenylborate anion is added as the water soluble sodium tetraphenylborate. The waste supernate contains about $2.5 \times 10^{-4} \mathrm{M}$ cesium and $0.02 \mathrm{M}$ potassium, and both are precipitated as the respective tetraphenylborate (TPB) salts. Over $98 \%$ of the $\mathrm{Cs}^{+} / \mathrm{K}^{+}$precipitate is the potassium salt. The precipitation reaction can be represented as:

$$
\mathrm{B}_{4^{-}}(\mathrm{aq})+\mathrm{Cs}^{+} / \mathrm{K}^{+}(\mathrm{aq})-\cdots \mathrm{Cs} / \mathrm{K} \mathrm{B} \emptyset_{4}(\mathrm{~s})
$$

The effects of several experimental variables on cesium removal via sodium tetraphenylborate precipitation have been studied. These variables include supernate feed composition $\left[\left(\mathrm{Na}^{+}\right)=2.8-6.2 \mathrm{M},\left(\mathrm{OH}^{-}\right)=1-3.8 \mathrm{M}\right.$, cesium activity $\left.=0.02-1.0 \mathrm{Ci} / \mathrm{L}\right]$, sodium tetraphenylborate excess, contact time, and purity of sodium tetraphenylborate. Sodium tetraphenylborate was added as a $0.5 \mathrm{M}$ solution in $0.01 \mathrm{M}$ sodium hydroxide. The decontamination facter (DF) for cesium ranges from $10^{4}$ to $10^{6}$ depending on the cesium and sodium concentrations in the feed. The expected DF values for cesium in salt supernate can be caiculated from the solubilities of cesium and sodium tetraphenylborate. The calculated Dif values agree well with values measured on actual supernate.

The cesium DF is affected strongly by the sodium and potassium ion concentrations. The concentration of hydroxide ion and the radioactivity level have only a minor effect on cesium DF. With a sodium tetraphenylborate excess of $0.015 \mathrm{M}$, a high cesium $\mathrm{DF}\left(>10^{5}\right)$ 
is always obtained when the supernate contains less than $3.5 \mathrm{M}$ sodium ion. However, the solubility product for sodium tetraphenylborate is exceeded when supernate containing more than $4.5 \mathrm{M}$ sodium is used. The cesium DF then varies with contact time because most of the tetrapheny borate anion added is precipitated at the high sodium concentration and is not available immediately to precipitate cesium. Sodium tetraphenylborate solubility decreases from about $0.9 \mathrm{M}$ in water to $0.00011 \mathrm{M}$ in supernate containing $7 \mathrm{M}$ sodium. A high cesium DF can be obtained if enough excess sodium tetraphenylborate is added and a longer contact time is used to allow the cesium to exchange with the sodium.

\section{ADSORPTION OF STRONTIUM AND ACTINIDES BY MONOSODIUM TITANATE}

Most of the strontium in the HLW is precipitated as strontium hydroxide in the sludge. The remaining concentration of soluble strontium in the supernate is about $2 \times 10^{-7} \mathrm{M}$. Strontium can be removed from the high sodium ion solution by the addition of monosodium titanate or MST $\left(\mathrm{NaTi}_{2} \mathrm{O}_{5} \mathrm{H}\right)$. The MST is an inorganic ion-exchanger developed by R. Dosch and coworkers at Sandia National Laboratory in the mid-1970's.

In alkaline solution, removal of strontium is reported to be a surface ion-exchange process between the sodium in the MST and the strontium in solution. The chemical reaction for this reaction is shown below;

$$
\mathrm{NaTi}_{2} \mathrm{O}_{5} \mathrm{H}(\mathrm{s})+\mathrm{Sr}^{2+}(\mathrm{aq})--->\quad \mathrm{Sr}\left(\mathrm{Ti}_{2} \mathrm{O}_{5} \mathrm{H}\right)_{2}(\mathrm{~s})+2 \mathrm{Na}^{+}(\mathrm{aq}) .
$$

In laboratory tests with excellent mixing, equilibrium is achieved in 48 hours upon contact of a test solution with the MST. Greater than $99 \%$ of the strontium is removed when a solution containing $2 \times 10^{-7} \mathrm{M}$ strontium is treated with 0.5 grams of MST per liter of solution.

Like strontium, most of the plutonium and uranium are in the sludge. However, small amounts of plutonium and uranium are soluble in the concentrated alkaline salt solutions. Tests have shown that both plutonium and uranium are removed from solution upon addition of MST. Greater than $90 \%$ of the plutonium and approximately $30 \%$ of the uranium are removed. However, because of the higher solubility of uranium, the loading of uranium onto the MST is larger than that of plutonium.

The mechanism of the removal of plutonium and uranium by the MST is not known conclusively. Preliminary results indicate that the removal of uranium may be a surface adsorption mechanism, whereas plutonium may be removed by either adsorption or ion-exchange or both. The removal of strontium and plutonium increases with temperature. In contrast, the removal of uranium decreases with increasing temperature. From competition experiments, the removal of plutonium and strontium are not affected by the presence of each other, but are decreased by the presence of uranium.

Because of the potential for the accumulation of fissile material by adsorption onto the MST, an assessment of the nuclear criticality safety during the ITP process has been carried out. The results of the analysis indicate that there is no credible potential for criticality. Because of the low solubility and low mass loading onto the MST, the amount of MST required to load a sufficient quantity of fissile material for a criticality incidient is more than that required to process all of the liquid HLW in the ITP process.

\section{CHEMICAL AND RADIOLYTICAL STABILITY OF POTASSIUM AND CESIUM TETRAPHENYLBORATE PRECIPITATE}

The precipitation process can be performed in existing waste tanks only if the K/Cs TPB precipitate remains chemically and radiolytically stable long enough to filter and wash it. Tests indicate that the precipitate is chemically stable in the alkaline salt solutions which will be produced during precipitation and washing. In the absence of a radiation field, the tetraphenylborate salts are stable for months in alkaline solutions and slurries at temperatures up to $70^{\circ} \mathrm{C}$.

The tetraphenylborate salts will hydrolyze under acidic conditions. However, acidic 
conditions are not produced during any stage of the HLW pretreatment operations carried out in the waste tanks. Acid hydrolysis will be utilized in the DWPF to decompose the precipitate and allow separation of the organic carbon from the remaining aqueous phase by steam distilling.

Gamma irradiation tests indicate that the insoluble K/Cs TPB precipitate is about 15 times more stable than sodium tetraphenylborate. At an expected dose rate of $2.7 \mathrm{~J} / \mathrm{kg}$-s, approximately $10 \%$ of the K/Cs TPB will decompose during one year of storage. Radiolytic decomposition products include in decreasing yield; benzene $(50 \%)$, phenol (25\%), biphenyl (20\%), and phenylboric acid (5\%). The effects of $\mathrm{K} / \mathrm{Cs}$ tetraphenylborate decomposition on the salt DF can easily be overcome by the presence of a small excess of sodium tetraphenylborate during the expected processing period. Degradation of the precipitate is still to be avoided for flammability, processing, and environmental considerations.

\section{FILTRATION OF ITP SLURRIES}

Cross-flow filtration was chosen for separation of the solid tetraphenylborate and sodium titanate from the decontaminated supernate (see Figure 4). Cross-flow filtration is recommended with low solids loading, relatively small particle size, and in cases where power costs for pressure operation are not a problem. During filtration the pressurized precipitate slurry is pumped down the filter tubes at high velocities. The filtrate weeps through the pores and is collected in the annular space between the filter tube and its housing.

The high linear velocity of the slurry helps sweep the filter surface clean and maintain high filtrate flux. The slurry is recycled to the precipitation/feed tank until the desired solid concentration is reached. The filter tubes can be backpulsed with air or other inert gas to remove solids any solids which have collected in the filter pores. In addition, a filter cleaning procedure has been developed for when a sufficient amount of solids has accumulated in the filter pores to result in a significant decrease in filtrate flux or very high pressure drops across the filter. When this occurs, the filter is first flushed with water, and then with a 2-4 wt.\% solution of oxalic acid. Oxalic acid dissolves solids in the filter pores, thereby reopening filter channels and restoring the desired filtrate flux and pressure drop across the filter. Flushing with sodium hydroxide solution has also be shown to be effective in cleaning plugged filters.

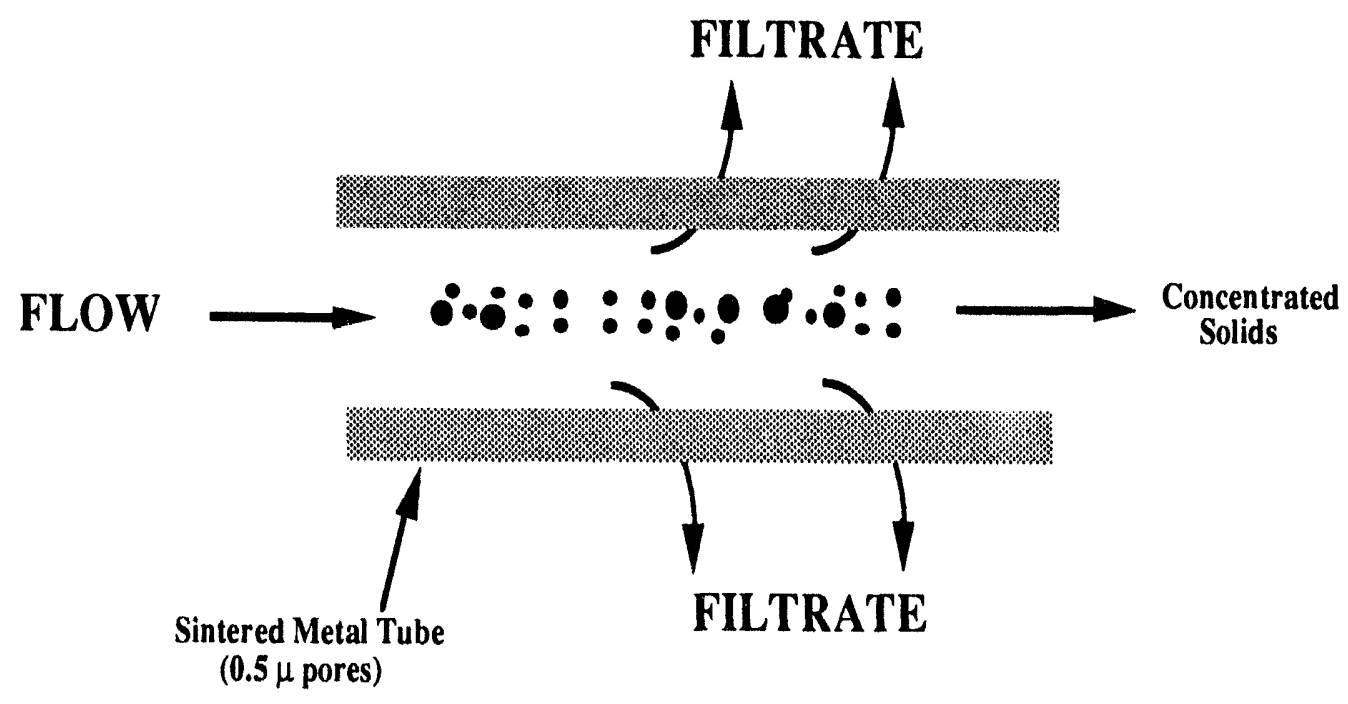

Figure 4. Schematic Drawing of Cross-Flow Filtration 


\section{FLAMMABILITY HAZARDS}

There are two flammability hazards associated with the ITP process; (1) combustion of dry K/Cs TPB solids and (2) ignition of flammable vapor mixtures of benzene and hydrogen. Liquid slurries, which are produced in the ITP process, are not ignitable because of their high water content. However, deposits of dry solids from the slurries are combustible and produce dense, black smoke when burned. As a result of the radiolytic decomposition of the K/Cs TPB precipitate and water, benzene and hydrogen will be produced during the ITP process. Benzene is volatile and flammable, with a lower flammable limit (LFL) of $1.2 \%(\mathrm{v} / \mathrm{v})$ in air. The LFL for hydrogen in air is $4.0 \%(\mathrm{v} / \mathrm{v})$. Engineering and administrative controls have been developed to prevent the combustion of dry solids and the accumulation of flammable vapor mixtures. All of the waste tanks are equipped with active ventilation systems which continuously purge the vapor space of the tank. In addition, these tank, as well as the cold chemical NaTPB storage tank, are blanketed with nitrogen to reduce the oxygen content to below that required to support combustion. In the event of loss of power, backup diesel generators are available to provide electrical power to the ventilation system. In the event of loss of installed blowers, dedicated portable blowers can be installed.

\section{FULL-SCALE ITP DEMONSTRATION}

A full-scale demonstration of this process was conducted in 1983 . In that demonstration 1.6 million liters of high-level radioactive supernate were transferred from Tank $24 \mathrm{H}$ to Tank $48 \mathrm{H}$, treated with sodium tetraphenylborate and monosodium titanatefor three days, and then the precipitate was filtered. A total of 2.0 million liters of decontaminated supernate were produced. The average ${ }^{137} \mathrm{Cs}$ activity of the decontaminated supernate was $7400 \mathrm{~d} / \mathrm{m} / \mathrm{ml}$. corresponding to a ${ }^{137} \mathrm{Cs}$ decontamination factor of 43,000 . After filtration, about 150,000 liters of concentrated precipitate remained, which was water washed to remove sodium salts and reconcentrated to $10 \mathrm{wt} . \%$ solids.

\section{CORROSION PREVENTION}

The successful pretreatment of all of the HLW stored at the SRS requires the use of eight carbon steel waste tanks over the life of the ESP and ITP processes. To ensure that the service life will meet the planned schedule of about 15 years to pretreat all of the currently stored waste, the chemical composition of the wastes will be closely monitored and corrosion inhibitors added as necessary to prevent corrosion. Corrosion monitors are also being developed to provide on-line indication of corrosive conditions within the waste tanks.

Laboratory tests indicate that localized or pitting corrosion can occur during ESP and ITP operations which could render the tanks unusable. Pitting corrosion occurs as a result of the dilution or depletion of corrosion inhibitors originally present in the waste. Aggressive species in the waste which enhance the rate of attack include nitrate, sulfate, chloride and fluoride[1]. Nitrite and hydroxide have been shown to be effective inhibitors against pitting corrosion even in dilute salt solutions[2]. Minimum concentrations for each inhibitor have been established over the range of waste compositions expected for each process.

Stress cracking corrosion during aluminum dissolution was also identified as a possible corrosion concern because of the high hydroxide concentrations and temperature. Laboratory tests have measured the potential for stress corrosion cracking over a wide range of waste compositions that may occur during aluminum dissolution. These tests indicate that stress corrosion cracking will not occur if the hydroxide concentration is maintained below 8.0 molar, the temperature is less than $100^{\circ} \mathrm{C}$, and there is a minimum nitrate concentration of 0.02 molar. These conditions provide a wide operating envelope for removing aluminum from wastes during the ESP operation. 


\section{SUMMARY}

Two processes, Extended Sludge Processing and In-Tank Precipitation, have been developed and demonstrated at full-scale to pretreat the Savannah River Site High-Level Waste for permanent disposal. These processes will be carried out in waste storage tanks which have been modified for chemical processing. These processes will concentrate the radioactivity into a small volume for vitrification. The bulk of the waste will be sufficiently decontaminated that it can be disposed of as a low-level waste. The highly radioactive fraction will be vitrified in the Defense Waste Processing Facility. The decontaminated waste will be incorporated into a cement wasteform in the Saltstone Facility.

\section{REFERENCES}

1. D. F. Bickford, J. W. Congdon, and S. B. Oblath, "Corrosion of Radioactive Waste Tanks Containing Washed Sludge and Precipitate," Materials Performance, 27(5), 16 (1988).

2. J. W. Congdon, "Inhibition of Nuclear Waste Solutions Containing Multiple Aggressive Anions," Materials Performance, 27(5), 34 (1988).

\section{ACKNOWLEDGEMENT}

The information contained in this article was developed during the course of work under Contract No. DE-AC09-89SR18035 with the U.S. Department of Energy. 


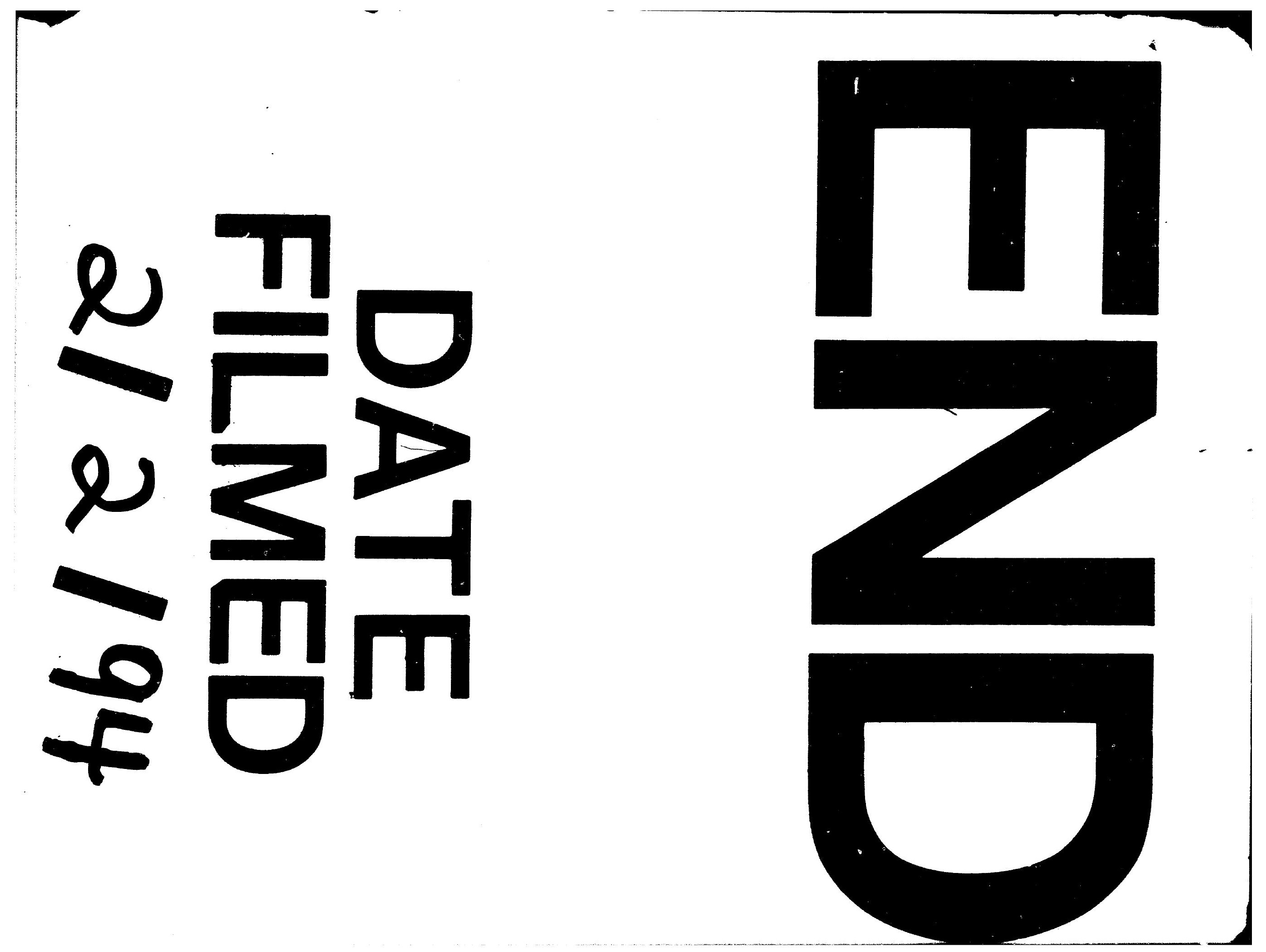

